Research

\title{
Endorsement of the CONSORT Statement by high impact factor medical journals: a survey of journal editors and journal 'Instructions to Authors'
} Sally Hopewell*1, Douglas G Altman ${ }^{1}$, David Moher ${ }^{2}$ and Kenneth F Schulz ${ }^{3}$

Address: ${ }^{1}$ Centre for Statistics in Medicine, University of Oxford, Oxford, UK, ${ }^{2}$ Chalmers Research Group, Children's Hospital of Eastern Ontario Research Institute, Ottawa, Canada; Department of Epidemiology and Community Medicine, Faculty of Medicine, University of Ottawa, Canada and ${ }^{3}$ Family Health International, P.O. Box 13950, Research Triangle Park, USA

Email: Sally Hopewell* - sally.hopewell@csm.ox.ac.uk; Douglas G Altman - doug.altman@csm.ox.ac.uk; David Moher -dmoher@uottawa.ca; Kenneth F Schulz - kshulz@fhi.org

* Corresponding author

Published: 18 April 2008

Trials 2008, 9:20 doi:10.1186/1745-62/5-9-20

This article is available from: http://www.trialsjournal.com/content/9/1/20

(c) 2008 Hopewell et al; licensee BioMed Central Ltd.

This is an Open Access article distributed under the terms of the Creative Commons Attribution License (http://creativecommons.org/licenses/by/2.0), which permits unrestricted use, distribution, and reproduction in any medium, provided the original work is properly cited.

\begin{abstract}
Background: The CONSORT Statement provides recommendations for reporting randomized controlled trials. We assessed the extent to which leading medical journals that publish reports of randomized trials incorporate the CONSORT recommendations into their journal and editorial processes.

Methods: This article reports on two observational studies. Study I: We examined the online version of 'Instructions to Authors' for 165 high impact factor medical journals and extracted all text mentioning the CONSORT Statement or CONSORT extension papers. Any mention of the International Committee of Medical Journal Editors (ICMJE) or clinical trial registration were also sought and extracted. Study 2: We surveyed the editor-in-chief, or editorial office, for each of the 165 journals about their journal's endorsement of CONSORT recommendations and its incorporation into their editorial and peer-review processes.
\end{abstract}

Results: Study I: Thirty-eight percent (62/165) of journals mentioned the CONSORT Statement in their online 'Instructions to Authors'; of these 37\% (23/62) stated this was a requirement, 63\% (39/62) were less clear in their recommendations. Very few journals mentioned the CONSORT extension papers. Journals that referred to CONSORT were more likely to refer to ICMJE guidelines (RR 2.16;95\% Cl I.5I to 3.08 ) and clinical trial registration (RR 3.67; 95\% Cl 2.36 to 5.7I) than those journals which did not.

Study 2: Thirty-nine percent (64/165) of journals responded to the on-line survey, the majority were journal editors. Eighty-eight percent (50/57) of journals recommended authors comply with the CONSORT Statement; $62 \%(35 / 56)$ said they would require this. Forty-one percent (22/53) reported incorporating CONSORT into their peer-review process and 47\% (25/53) into their editorial process. Eighty-one percent (47/58) reported including CONSORT in their 'Instructions to Authors' although there was some inconsistency when cross checking information on the journal's website. Sixty-nine percent $(31 / 45)$ of journals recommended authors comply with the CONSORT extension for cluster trials, $60 \%$ (27/45) for harms and $42 \%$ (19/45) for noninferiority and equivalence trials. Few journals mentioned these extensions in their 'Instructions to Authors'.

Conclusion: Journals should be more explicit in their recommendations and expectations of authors regarding the CONSORT Statement and related CONSORT extensions papers. 


\section{Background}

It is over ten years since the CONSORT (Consolidated Standards of Reporting Trials) Statement was first published in 1996 [1] providing recommendations for reporting parallel group randomized controlled trials (RCTs). CONSORT provides recommendations for authors regarding how to prepare reports of trial findings, facilitating their complete and transparent reporting, and aiding their critical appraisal and interpretation. It has been endorsed by the World Association of Medical Editors (WAME), the International Committee of Medical Journal Editors (ICMJE), the Council of Science Editors (CSE), and well over 200 journals worldwide [2]. The revised CONSORT Statement of 2001 [3] has been translated into several languages and cited in journals over 1,300 times.

In addition to the CONSORT Statement, which provides recommendations for reporting parallel group randomized trials, extensions have been developed to give additional guidance for randomized trials with specific designs, data and interventions. These included the CONSORT extensions for cluster trials [4], non-inferiority and equivalence trials [5], herbal interventions [6], non-pharmacological interventions [7], abstracts [8] and harms [9].

Several studies have assessed the impact of using the CONSORT Statement to improve the reporting of RCTs in journal articles. Eight studies were summarized in a systematic review by Plint and colleagues [10], who concluded that journal adoption of the CONSORT Statement is associated with improved reporting of randomized trials although poor reporting remains common.

In 2003, Altman conducted a study of journal endorsement of the CONSORT Statement and found that seven years following its initial publication, and two years after its update, only $22 \%$ of 166 high impact factor journals provided any mention of CONSORT in their published 'Instructions to Authors' [2]. Four years have elapsed since this journal endorsement survey and we believe it is again timely to assess the impact of the CONSORT Statement and determine the extent to which journals that publish reports of randomized trials incorporate the CONSORT recommendations into their journal and editorial processes.

\section{Objectives}

We set out to determine the extent to which leading medical journals incorporate the CONSORT Statement and related extension papers in their published 'Instructions to Authors'. We also sought to survey journal editors' opinions about endorsement of the CONSORT Statement and related CONSORT extension papers and their incorporation into the editorial and peer-review process.

\section{Methods \\ Sample}

Journals were selected using the strategy adopted by Altman [2]. Using citation impact factors (via ISI Web of Knowledge) for 2006, we identified the top five journals from each of the 33 medical specialties and the top 15 journals for general and internal medicine. Journals that did not publish clinical research (based on explicit statement or inspection of journal contents) were excluded and replaced by the next one on the list.

\section{Survey of journals' published 'Instructions to Authors'}

For each of the journals in the sample, we examined the 'Instructions to Authors' published on the journal's website (searched between July and October 2007) and extracted all text mentioning CONSORT or CONSORT extension papers (cluster, non-inferiority and equivalence, herbal and harms). Any mention of the ICMJE's 'Uniform Requirements for Manuscripts Submitted to Biomedical Journals' or reference to clinical trial registration were also sought and extracted.

\section{Survey of journal editors}

For each of the journals in the sample, we contacted via email the editor-in-chief, or editorial office if contact details for this person were not available (depending on the contact information included on the journal website), asking them to complete a short on-line survey (conducted between 6 August and 8 October 2007 using Survey Monkey). Two email reminders were sent to encourage editors to complete the on-line survey. The survey asked about their journal's endorsement of the CONSORT Statement, whether CONSORT is included in their 'Instructions to Authors', and if it is incorporated into their editorial and peer-review processes and, if so, how. Journal editors were also asked whether they recommended or required authors to comply with any of the CONSORT extension papers (cluster, non-inferiority and equivalence, herbal and harms). The on-line survey of journal editors' endorsement of CONSORT allows a direct comparison with what is reported in their journal's published 'Instructions to Authors' on their journal's website.

\section{Results}

One hundred and eighty journals were identified, of which 15 were duplicates (i.e. listed in another medical speciality) and excluded; 165 journals were included in our sample.

\section{Survey of journals' published 'Instructions to Authors'}

Of the 165 journals, 62 (38\%) mentioned the CONSORT Statement in their 'Instructions to Authors' published on their journal's website. This is a relative increase of $73 \%$ from the survey in 2003 [2], when 36 (22\%) of the 166 journals provided any mention of CONSORT. One-hun- 
dred and twenty-one journals were included in both the 2003 and 2007 samples; of these, 32 (26\%) of 121 journals in 2003 provided any mention of CONSORT compared to 47 (39\%) in 2007, a relative increase of 50\%.
Twenty-three of the 62 journals that mentioned the CONSORT Statement in their 'Instructions to Authors' stated that this was a requirement of their journal (i.e. authors must conform to the CONSORT Statement) (Table 1). Of

Table I: Mentioned in journals published 'Instructions to Authors'

\begin{tabular}{|c|c|}
\hline & $N=165(\%)$ \\
\hline CONSORT Statement & $62(38 \%)$ \\
\hline Require & 23 \\
\hline Recommend & 39 \\
\hline Submit with checklist & 17 \\
\hline Web address & $46 *$ \\
\hline 2001 journal article & 18 \\
\hline 2001 exploratory article & 1 \\
\hline Article citing $200 \mathrm{I}$ article & 2 \\
\hline I 996 journal article (out-of-date) & $6 * *$ \\
\hline Cluster extension & $5(3 \%)$ \\
\hline Require & 3 \\
\hline Recommend & 2 \\
\hline Suitable reference & 2 \\
\hline Harms extension & $3(2 \%)$ \\
\hline Require & 2 \\
\hline Recommend & 1 \\
\hline Suitable reference & 1 \\
\hline Herbal extension & $2(1 \%)$ \\
\hline Recommend & 2 \\
\hline Suitable reference & 2 \\
\hline Non-inferiority and equivalence extension & $I(1 \%)$ \\
\hline Recommend & 1 \\
\hline Suitable reference & 1 \\
\hline ICMJE & $69(42 \%)$ \\
\hline Web address & 48 \\
\hline Suitable reference (article > 2000) & 3 \\
\hline Obsolete reference (article < 2000) & 15 \\
\hline No reference & 6 \\
\hline Trial registration & $61(37 \%)$ \\
\hline Require & 44 \\
\hline Recommend & 17 \\
\hline Cites http://www.icmje.org & 23 \\
\hline Cites http://www.clinicaltrials.gov & 9 \\
\hline Cites WHO International Clinical Trial Registry Platform & 4 \\
\hline Cites a combination of the above & 10 \\
\hline
\end{tabular}

* Web address was misspelt $(\mathrm{n}=2)$

** Article citing the 1996 article $(\mathrm{n}=1)$ 
these, 17 stated that they required a completed CONSORT checklist to be submitted with the manuscript as a condition of the submission. The remaining 39 journals were less clear in their recommendations and included phrases such as authors "should consult the CONSORT guidelines" or "we encourage authors to follow the CONSORT Statement". Very few journals provided any mention of the CONSORT extension papers (cluster $(n=5)$, non-inferiority and equivalence $(\mathrm{n}=1)$, herbal $(\mathrm{n}=2)$ and harms $(\mathrm{n}=3))$.

The majority of journals $(n=46)$ mentioning the CONSORT Statement gave the web address [11], while 18 referred to the latest version of the publication. Only one journal referred to the full explanatory publication [12], however, and six journals still referred to the out-of-date 1996 Statement [1].

Of the 165 journals, 69 (42\%) referred to the ICMJE guidelines in their published 'Instructions to Authors'. This is a slight decrease from when this survey was last carried out in 2003, when 72 of the 166 (43\%) journals referred to the ICMJE guidelines. The majority of journals ( $\mathrm{n}=48)$ referred to ICMJE the web address, including three which also referred to a recent publication. The remaining 15 journals cited an obsolete journal publication (i.e. published before 2000), while six included no reference. Journals that referred to CONSORT were much more likely to refer to the ICMJE guidelines $(39 / 62 ; 63 \%)$ than those journals that did not refer to CONSORT (30/ 103; 29\%) (relative risk 2.16; 95\% confidence interval (CI) 1.51 to 3.08 ).

Sixty-one (37\%) of the 165 journals mentioned clinical trial registration in their 'Instruction to Authors', of which
44 specifically stated that all recent clinical trials must be registered as a requirement of submission to that journal. A further 17 journals were less clear in their recommendations and, while they encouraged clinical trial registration, this was not a specific requirement. Cited sources of information about trial registration included the ICMJE web address $(n=23)$, ClinicalTrials.gov $(n=9)$ and the WHO International Clinical Trials Registry Platform $(n=4)$; the other 10 journals cited a combination of these sources. Again, journals that referred to CONSORT were much more likely to mention clinical trial registration (42/62; $68 \%$ ) than those journals that did not refer to CONSORT $(19 / 103 ; 18 \%$ ) (relative risk $3.67 ; 95 \%$ CI 2.36 to 5.71 ).

Those journals which provided some mention of the CONSORT Statement in their 'Instructions to Authors' were also much more likely to include information about other reporting guidelines. These included QUOROM $(13 / 165 ; 8 \%)$, MOOSE $(7 / 165 ; 4 \%)$, REMARK $(1 / 165$; $1 \%)$, STROBE $4 / 165 ; 2 \%)$ and TREND $(1 / 165 ; 1 \%)$; all mentioned CONSORT in their 'Instructions to Authors'.

\section{Survey of journal editors}

Responses were received from 64 (39\%) of the 165 journals to the on-line survey of journal editors about endorsement of the CONSORT Statement and related CONSORT extension papers (not all journals responded to each section of the survey). The majority of responders were journal editors (Table 2). Thirty-nine $(61 \%)$ of the 64 responders reported that the CONSORT Statement was mentioned in the 'Instructions to Authors' on their journal's website.

For $50(50 / 57 ; 88 \%)$ journals, responders said that their journal recommended that authors comply with the

Table 2: Survey of journals editors' endorsement of the CONSORT Statement

\begin{tabular}{lc}
\hline & $\mathbf{N}=\mathbf{6 4 *}(\%)$ \\
\hline Person completing survey & $18(28 \%)$ \\
$\quad$ Editor in chief & $17(27 \%)$ \\
$\quad$ Managing editor & $7(11 \%)$ \\
$\quad$ Associate editor & $4(6 \%)$ \\
Editor & $16(25 \%)$ \\
$\quad$ Administrator & $2(3 \%)$ \\
Other (director) & $50 / 57(88 \%)$ \\
\hline Journal recommends authors comply with the CONSORT Statement & $2 / 57(3 \%)$ \\
$\quad$ Not applicable & $35 / 56(62 \%)$ \\
Journal requires authors comply with the CONSORT Statement & $2 / 56(4 \%)$ \\
$\quad$ Not applicable & $47 / 58(81 \%)$ \\
Journal mentions the CONSORT Statement in its 'Instructions to Authors' & $2 / 58(3 \%)$ \\
$\quad$ Not applicable & $22 / 53(41 \%)$ \\
Journal incorporates the CONSORT Statement in its peer review process & $25 / 53(47 \%)$ \\
$\quad$ Journal incorporates the CONSORT Statement in its editorial process & \\
\hline
\end{tabular}

* Some responders did not complete all sections of the survey. 
CONSORT Statement; for 35 (35/56; 62\%) journals this was a requirement (Table 2). Most respondents (47/58; $81 \%$ ) also said that their journal mentioned the CONSORT Statement in its 'Instructions to Authors'. However, there is some inconsistency, as when subsequently cross checking the information provided on the journal's website under 'Instructions to Authors', 11 of the 47 journals provided no mention of the CONSORT Statement despite indicating in the on-line survey that they did.

Just under half of journals $(22 / 53 ; 41 \%)$ said that they incorporated the CONSORT Statement into their peerreview process. A similar proportion of journals $(25 / 53$; $47 \%$ ) said that they incorporated the CONSORT Statement into their editorial process. Examples of how this was achieved include "requiring authors to include a CONSORT flow diagram and completed checklist with their manuscript submission", "editors pre-screening and returning non compliant manuscripts directly to the authors", "including the CONSORT checklist for download on the peer review website alongside the submitted manuscript", "including information about the CONSORT Statement in the instructions for peer review", and "including the CONSORT Statement as part of the editorial checklist".

Journal editors were also asked about their journal's endorsement of extensions to the CONSORT Statement. Thirty-one (69\%) journals said that their journal recommended authors comply with the CONSORT extension for cluster trials; 22 (49\%) journals said that they would require this (Table 3 ). Twenty-seven $(60 \%)$ said that their journal recommended authors comply with the CONSORT extension for harms and $18(40 \%)$ said that they would require this. Nineteen $(42 \%)$ journals said that their journal recommended authors comply with the CONSORT extension for non-inferiority and equivalence trials whereas $13(29 \%)$ journals said that they would require this. The CONSORT extension for herbal interventions was not as widely endorsed as it was not applicable for some journals.

Despite journal editors' responses about extensions to the CONSORT Statement, few actually mentioned these extensions in their 'Instructions to Authors' (Table 3).

\section{Discussion}

The CONSORT Statement aims to improve the quality of reports of randomized trials. It is encouraging that over a third (38\%) of high impact factor journals, assessed in our study, refer to the CONSORT Statement in their published 'Instruction to Authors'. This represents a relative increase of $73 \%$ since this study was last conducted in 2003 when only $22 \%$ of journals mentioned CONSORT in their 'Instruction to Authors' [2]. Some journals, however, still refer to the superseded 1996 version of the CONSORT Statement and we would encourage journals to keep their 'Instructions to Authors' up-to-date.

There is, however, still ambiguity in the wording of some journals' published 'Instructions to Authors' as to whether they require, or recommend, that authors comply with the CONSORT Statement [2]. We believe that journals should provide a clear message to their authors and recommend authors submit a completed CONSORT flow diagram and checklist as a requirement to submission in an endorsing journal. Only by endorsement of the CONSORT Statement by more journals, and greater editorials efforts to

Table 3: Survey of journals editors' endorsement of extensions to the CONSORT Statement *

\begin{tabular}{|c|c|c|c|}
\hline & Yes & No & Not applicable \\
\hline \multicolumn{4}{|c|}{ Journal recommends authors comply with the CONSORT } \\
\hline Cluster extension & $31(69 \%)$ & $10(22 \%)$ & $4(9 \%)$ \\
\hline Harms extension & $27(60 \%)$ & II (24\%) & 7 (16\%) \\
\hline Herbal extension & $13(29 \%)$ & $10(22 \%)$ & $22(49 \%)$ \\
\hline Non-inferiority and equivalence extension & $19(42 \%)$ & $12(27 \%)$ & $14(31 \%)$ \\
\hline \multicolumn{4}{|c|}{ Journal requires authors comply with the CONSORT } \\
\hline Cluster extension & $22(49 \%)$ & $16(36 \%)$ & $7(15 \%)$ \\
\hline Harms extension & $18(40 \%)$ & $18(40 \%)$ & $9(20 \%)$ \\
\hline Herbal extension & $12(26 \%)$ & $14(30 \%)$ & $20(44 \%)$ \\
\hline Non-inferiority and equivalence extension & $13(29 \%)$ & $17(39 \%)$ & $14(32 \%)$ \\
\hline \multicolumn{4}{|c|}{ Journal mentions CONSORT extension in its 'Instructions to Authors' } \\
\hline Cluster extension & $12(27 \%)$ & $28(62 \%)$ & $5(11 \%)$ \\
\hline Harms extension & $10(22 \%)$ & $29(65 \%)$ & $6(13 \%)$ \\
\hline Herbal extension & $5(12 \%)$ & $24(56 \%)$ & $14(32 \%)$ \\
\hline Non-inferiority and equivalence extension & $5(12 \%)$ & $28(65 \%)$ & $10(23 \%)$ \\
\hline
\end{tabular}

* Some responders did not complete all sections of the survey. 
ensure that authors comply, can the quality of reporting of randomized trials published in leading journals be improved [10].

In September 2004, the members of the ICMJE published a joint editorial stating that they would only consider a trial for publication if it has been registered before the enrolment of the first patient [13]. In our study, over a third (37\%) of journals required recent clinical trials to be registered as a requirement of submission to that journal. Disappointingly, a number of these journals did not provide the same endorsement of the CONSORT Statement despite recognising the importance of trial registration which, by itself, is not the best marker of trial quality.

It is also disappointing that so few journals endorse the recent extensions to the CONSORT Statement [4-6,9]. These extensions reflect a considerable amount of work and were developed to improve the reporting and transparency of trials using specific designs and types of data. Other CONSORT extensions have very recently been published $[7,8]$ and others are being developed. We would recommend that journals reference these extensions in their 'Instructions to Authors' thereby helping authors wanting to improve the reporting of their randomized trials.

One obvious limitation of our study is that, despite several electronic reminders, there was a poor response rate $(39 \%)$ to the on-line survey of journal editors' endorsement of CONSORT. As might be expected journals which endorsed CONSORT were more likely to respond (61\%) to the survey than those journals which did not (39\%). However, despite this limitation the results of this survey are still of interest, in particular, to those journals who said they would require, or recommend, authors comply with the CONSORT Statement but do not mention this in their 'Instructions to Authors'. This is particularly apparent for CONSORT extensions. In response to the survey two journal editors said that they were in the process of updating their journals' 'Instructions to Authors'. It is possible that these instructions were updated during the study period; however, the numbers are very small and would not affect our results. We note however, that there was inconsistency between editors' responses and the information on the journal's website under 'Instructions to Authors', especially in relation to the support of extensions to CONSORT.

Similar to the CONSORT Statement for reporting the results of randomized trials, other reporting guidelines exist which provide advice on how to report research methods and findings for other types of study designs. In our study journals which endorsed the CONSORT Statement were more likely to endorse other reporting guide- lines, although the numbers were very low. The EQUATOR Network [14] is a new initiative which aims to increase awareness of good reporting guidelines in health research and thus improve the quality of scientific publications. We hope the work of this initiative will lead to better endorsement by journals of these important reporting guidelines.

\section{Conclusion}

In summary, we believe that the CONSORT Statement, and its related extensions papers, will only continue to improve the quality of reports of randomized trials, if more journals endorse this initiative and, most importantly, require authors to comply as a condition of publication. The most obvious route through which this could be achieved is for journals to incorporate the CONSORT checklist and flow diagram into their editorial and peerreview processes and reflect this requirement in their published 'Instructions to Authors'. Without wide endorsement of the CONSORT Statement it cannot fully yield the benefits for which it was intended.

\section{Competing interests}

All authors are involved in many initiatives in health care and healthcare research which should benefit from a wide uptake of the CONSORT Statement and related extensions. DGA, DM and KFS form the CONSORT Executive. $\mathrm{SH}$ is funded by a grant to support the work of the CONSORT Group.

\section{Authors' contributions}

SH was involved in the design, implementation, analysis of the study, and in writing and commenting on drafts on the final manuscript. DGA, DM and KFS were involved in the design of the study and commenting on drafts on the final manuscript.

\section{Acknowledgements}

We are very grateful to all those who responded to the on-line survey. The CONSORT website and list of CONSORT endorsing journals has recently been updated as a result of this study. This study has been carried out as part of a grant to support the work of the CONSORT Group, funded by the National Coordinating Centre for Research Methodology on behalf of the Department of Health in the UK. DM is funded by a University of Ottawa Research Chair.

\section{References}

I. Begg C, Cho M, Eastwood S, Horton R, Moher D, Olkin I, Pitkin R, Rennie D, Schulz KF, Simel D, Stroup DF: Improving the quality of reporting of randomized controlled trials: the CONSORT statement. JAMA 1996, 276(8):637-639.

2. Altman DG: Endorsement of the CONSORT statement by high impact medical journals : survey of instructions for authors. BMJ 2005, 330(7499): I056-1057.

3. Moher D, Schulz KF, Altman DG, for the CONSORT Group: The CONSORT statement: revised recommendations for improving the quality of reports of parallel-group randomised trials. Lancet 200I, 357(9263): I I9I-II94. 
4. Campbell MK, Elbourne DR, Altman DG, for the CONSORT Group: CONSORT statement: extension to cluster randomised trials. BMJ 2004, 328(744I):702-708.

5. Piaggio G, Elbourne DR, Altman DG, Pocock SJ, Evans SJW, for the CONSORT Group: Reporting of noninferiority and equivalence randomized trials: an extension of the CONSORT statement. JAMA 2006, 295(I0): I I52-I I 60.

6. Gagnier JJ, Boon H, Rochon P, Moher D, Barnes J, Bombardier C, for the CONSORT Group: Reporting randomized, controlled trials of herbal interventions: an elaborated CONSORT statement. Ann Intern Med 2006, I 44(5):364-367.

7. Boutron I, Moher D, Altman DG, Schulz K, Ravaud P, for the CONSORT Group: Extending the CONSORT Statement to randomized trials of nonpharmacologic treatment: an explanation and elaboration. Ann Intern Med 2008, 148:295-309.

8. Hopewell S, Clarke M, Moher D, Wager E, Middleton P, Altman DG, Schulz KF, and the CONSORT Group: CONSORT for reporting randomized controlled trials in journal and conference abstracts: explanation and elaboration. PLOS Med 2008, 5(I):e20.

9. Ioannidis JP, Evans SJ, Gotzsche PC, O'Neill RT, Altman DG, Schulz K, Moher D, for the CONSORT Group: Better reporting of harms in randomized trials: an extension of the CONSORT statement. Ann Intern Med 2004, I 4 I ( I 0):78I-788.

10. Plint AC, Moher D, Morrison A, Schulz K, Altman DG, Hill C, Gaboury I: Does the CONSORT checklist improve the quality of reports of randomised controlled trials? A systematic review. Med J Aust 2006, I85(5):263-267.

II. CONSORT: transparent reporting of trials. [http://www.con sort-statement.org]. Accessed 20 February 2008

12. Altman DG, Schulz KF, Moher D, Egger M, Davidoff F, Elbourne D, Gøtzsche PC, Lang T, for the CONSORT Group: The revised CONSORT statement for reporting randomized trials: explanation and elaboration. Ann Intern Med 200I, 134(8):663-694.

13. De Angelis C, Drazen JM, Frizelle FA, Haug C, Hoey J, Horton R, Kotzin S, Marusic A, Sahni P, Schroeder TV, Sox HC, Van der Weyden MB, Verheugt FW: Clinical trial registration: a statement from the International Committee of Medical Journal Editors. Ann Intern Med 2004, I 4 I (6):477-478.

14. EQUATOR Network: Enhancing the QUAlity and Transparency Of health Research. [http://www.equator-network.org] Accessed 20 February 2008
Publish with Biomed Central and every scientist can read your work free of charge

"BioMed Central will be the most significant development for disseminating the results of biomedical research in our lifetime. "

Sir Paul Nurse, Cancer Research UK

Your research papers will be:

- available free of charge to the entire biomedical community

- peer reviewed and published immediately upon acceptance

- cited in PubMed and archived on PubMed Central

- yours - you keep the copyright
BioMedcentral 